\title{
In vitro antifungal potential of plant extracts against Fusarium oxysporum, Rhizoctonia solani and Macrophomina phaseolina.
}

Ramaraju Cherkupally*1, Srinivasa Reddy Kota ${ }^{2}$, Hindumathi Amballa ${ }^{3}$, Bhumi Narasimha Reddy ${ }^{4}$

*1\&2 Department of Botany, K.R.R. Govt. Arts and Science College, Kodad, Telangana, India.

${ }^{2 \& 3}$ Department of Botany, Osmania University, Hyderabad. Telangana, India.

Received: 2017-08-9; Accepted: 2017-08-27

\begin{abstract}
The antifungal activity of aqueous extracts of nine plants viz, Azadirachta indica, Parthenium bysterophorus, Momordica charantia, Allium sativum, Eucalyptus globules, Calotropis procera, Aloe vera, Beta vulgaris and Datura stramonium were assessed in vitro against Fusarium oxysporum f. sp. melongenae, Rhizoctonia solani and Macrophomina phaseolina, the soil borne phytopathogens. The assessment of fungitoxic effect was carried out by using three different concentrations i.e., 5, 10 and $20 \%$ against the test fungi, in terms of percentage of mycelial growth inhibition. The extract of $A$. sativum completely inhibited the mycelial growth of $M$. phaseolina at all the concentrations. The extracts of $D$. stramonium and $E$. globulus inhibited the mycelial growth of R. solani of $72 \%$, and $70.7 \%$ respectively at $20 \%$ concentration, that of $A$. sativum, E. globulus and D. stramonium exhibited inhibition percentage of $63.3 \%, 61.8 \%$ and $61.1 \%$ respectively at $20 \%$ concentration on Fusarium oxysporum f. sp. melongenae. The application of plant extracts for disease management could be less expensive, easily available, non-polluting and eco-friendly.
\end{abstract}

Keywords: Fusarium oxysporum, Rbizoctonia solani, Macrophomina phaseolina, phytopathogens, antifungal activity

\section{Introduction}

Brinjal (Solanum melongina L.) is grown as a vegetable crop in India and the plant is affected by various fungal diseases which in turn produces low crop yield. Among the fungal diseases caused by Fusarium oxysporum, Macrophomina phaseolina and Rhizoctonia solani are the major constraints in fruit field. Fusarium oxysporum f. sp. melongenae (Fom) is the most destructive pathogen causing Fusarium wilt of brinjal. This soil-borne fungus invades the vascular bundles, causes severe wilting and death of the above ground parts of plants by blocking the xylem transport system (Altınok, 2005). The pathogen Rhizoctonia solani causing germination failure, damping off and seedling rot is the major constraint to brinjal cultivation (Seema and Devaki, 2010). Macrophomina phaseolina causing charcoal rot is cosmopolitan in distribution and is potential threat to crop production in arid regions (Hoes, 1985).

Various disease management methods have been implemented to combat and eradicate pathogenic fungi. These include cultural, regulatory, physical, chemical and biological methods (Kata, 2000). Pathogens being soil borne, causes a huge problem in controlling the diseases. Synthetic chemicals used to control plant diseases not only pollute the environment, but are also harmful to human health. Intensive use of fungicides for the control of plant diseases has resulted in the accumulation of toxins to human beings as well as to the environment. Restrictions on the use of chemical pesticides have

${ }^{*}$ Corresponding Author:

Dr. Ramaraju Cherkupally,

Assistant Professor, Department of Botany,

K.R.R. Govt. Arts and Science College,

Kodad, Telangana, India.

E-mail: ramaraj.e789@gmail.com been increasing. Knowing the ill effects of these chemical residues found in eatables, plant growers are being challenged to maintain plant health with reduced input from agricultural chemicals.

Use of natural products for the management of fungal diseases in the plants is considered as a good alternate to synthetic fungicides, due to their less negative impact on the environment. Many higher plants and their constituents have been successful in plant disease control and proved to be safe and non-phytotoxic. Plant serves as renewable natural resources for a variety of biologically active chemicals. These chemicals bear a variety of properties viz, antibacterial, antifungal, antiviral, antihelminthic, anticancer, sedative, laxative, cardio tonic, diuretic and others (Parajuli et al., 1998).

Because of environmental and economic considerations, plant scientists are involved to find the cheaper and more environmental friendly biocompounds for the control of plant diseases using extracts from different plants (Gerresten and Haagsma, 1951; Kumar et al., 1979; Naidu and John, 1982). Thus, control strategies are now directed towards the use of natural products. Botanical pesticides are cheaper than their synthetic counter parts and their crude extracts are easy to prepare even by farmers. These are also less likely to the development of resistance or resurgence in pests. The benefits of natural pesticides have aroused 
interest in protection of crop plants. Keeping in view, the plant extracts were evaluated in vitro for their antifungal activity against, Fusarium oxysporum, Rhizoctonia solani and Macrophomina phaseolina.

\section{Materials and Methods}

Test fungus

The three pathogens viz., Fusarium oxysporum f. sp. melongenae (Fom), Rbizoctonia solani (Rs), and Macrophomina phaseolina (Mp) were selected for the experimental work. Parts of plants with symptoms of fusarium wilt, damping off, root rot, dry root rot, charcoal rot, stem canker were surface sterilized with $70 \%$ ethanol and immersion in $0.3 \%$ sodium hypochlorite for $10 \mathrm{~min}$, rinsed thoroughly in sterile distilled water and transferred to potato dextrose agar (PDA) medium. Plates were incubated at $26 \pm$ $2^{\circ} \mathrm{C}$ and observed daily for emergence of colonies. Sub-culturing was done from single spore to obtain pure culture. The pure culture of the test fungus was maintained on PDA slants and stored at $4^{\circ} \mathrm{C}$ in the refrigerator.

\section{Collection of Plant Material}

Fresh disease-free plant parts were collected locally. Selected plants were available in sufficient quantities. Nine native plants were selected in the present study, to evaluate their antifungal activity. The plants were selected from local flora on the basis of criteria such as the presence of antimicrobial properties according to literature, easy availability in bulk with very little commercial value. The selected plants were well adapted to the climatic conditions and were well known, among local natives, for their medicinal properties. The plants were identified by using standard flora (Pullaiah, 2015) and by comparison with herbaria of Department of Botany, Osmania University, Hyderabad, India. The plants and their parts used in the study are shown in Table 1.

Table 1. The aqueous plant extracts tested against mycelial radial growth of fungal phytopathogens.

\begin{tabular}{lllll}
\hline Common name & Local name & Botanical name & Family & Plant part used \\
\hline Neem & Vepa & Azadirachta indica A.Juss. & Meliaceae & leaves \\
Congress weed & Vayyari bama & Parthenium hysterophorus.L & Asterceae & twigs with leaves and flowers \\
Bitter gourd & kakara & Momordica charantia L. & Cucurbitaceae & leaves \\
Garlic & Ellipayalu & Allium sativum L & Allium sativum L & cloves \\
Blue gum & Eucaliptus & Eucalyptus globules Labill & Myrtaceae & leaves \\
Milk weed & Jilledu & Calotropis procera (Aiton) Dryand & Apocynaceae & leaves \\
Indian aloe & Kalabanda & Aloe vera (L.) Burm.f. & Asphodelaceae & leaves \\
Beet root & Beet root & Beta vulgaris L. & Amaranthaceae & Storage root \\
Devil's snare & Ummetta & Datura stramonium L. & Solanaceae & leaves \\
\hline
\end{tabular}

\section{Preparation of aqueous extract}

The leaves of Azadirachta indica, Parthenium bysterophorus, Momordica charantia, Eucalyptus globules, Calotropis procera, Aloe vera and Datura stramonium, root of Beta vulgaris, bulb (clove) of Allium sativum were washed with tap water followed by sterilised distilled water. $100 \mathrm{gm}$. of fresh leaves/bulb of each plant were taken, washed thoroughly and crushed in $100 \mathrm{ml}$ of sterilized distilled water $(1: 1 \mathrm{v} / \mathrm{v})$ and were ground separately in an electric grinder. In order to remove plant debris, the extracts were passed through a muslin cloth and the filtrate was centrifuged for 10 minutes at $5000 \mathrm{rpm}$ and the clear supernatant was collected. Then this material was taken in a beaker and boiled at $80^{\circ} \mathrm{C}$ for twenty minutes in a hot water bath. The stock solution, thus obtained was used for evaluating their antifungal activity and it was designated as $100 \%$. From this standard / stock solution(s), required concentrations $(5 \%, 10 \%$ and $20 \%)$ were prepared by adding sterile distilled water to PDA before use.

\section{Antifungal assay}

The plant extracts were evaluated at three concentrations $(5 \%, 10 \%$ and $20 \%)$ for their antifungal activity. To study the antifungal mechanism of plant extracts by using poisoned food technique (Nene and Thapliyal, 1993). Extracts were added in potato dextrose agar (PDA) medium at $5 \%, 10 \%$ and $20 \%$ concentration into petri dishes. PDA medium added only with sterile distilled water served as control. Each Petri dish was inoculated with $6 \mathrm{~mm}$ plug of isolate taken from margins of actively growing culture of pathogen. Then Petri plates were incubated at $25^{\circ} \pm 2^{\circ} \mathrm{C}$. Mycelial growth was recorded when the growth of pathogens were completed $(90 \mathrm{~mm})$ in the control plates. Each treatment was repeated three times.

\section{Statistical analysis}

Per cent inhibition in growth was determined with the help of mean colony diameter and calculated by using the following formula suggested by Vincent (1947).

$$
\text { Mycelial growth inhibition (\%) }=\frac{\mathrm{C}-\mathrm{T}}{\mathrm{C}} \times 100
$$

Where, $\mathrm{C}=$ Radial growth of the pathogen $(\mathrm{mm})$ in control; $\mathrm{T}=$ Radial growth of the pathogen $(\mathrm{mm})$ in treatment

\section{Results}

Inhibition in radial mycelial growth of Fom, Rs and Mp induced by plant extracts showed considerable difference in performance.

Effect of different plant extracts on radial mycelial growth of Fusarium oxysporum f. sp. melongenae

The highest percentage inhibition in radial mycelial growth was induced by Fom exhibited by $A$. sativum (63.3\%), followed by E. globulus (61.8\%), D. 
stramonium (61.1\%), M. charantia (24.4\%), A. vera (16.6\%), P. histerophorus (30.0\%), B. vulgaris (9.2\%), $A$. indica and Calotropis (0.0\%), (Table 2). $D$. stramonium (61.1), $A$. vera (16.6), and $A$. indica exhibited no inhibition of radial growth at all the experimental concentrations. $P$. hysterophorus, $M$. charantia, E. globules, B. vulgaris, A. sativum exhibited increasing percentage inhibition with increase in concentration of the extract (Table 2).

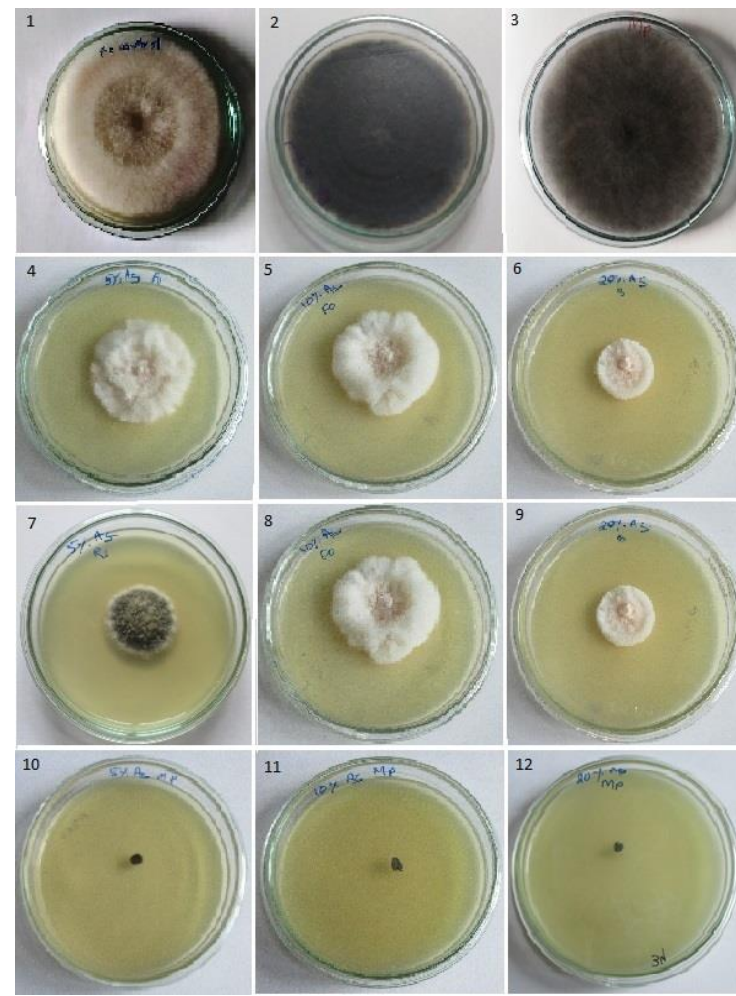

Plate 1. Fig. 1-3: Control petriplates of Fusarium oxysporum, Rhizoctonia solani, Macrophomina phaseolina, petriplates showing effect of Allium sativum at 5\%, 10\%, 20\% concentrations- Figs. 4-6: on Fom, 7-9: on R. solani, 10-12: on M. phaseolina.

Effect of different plant extracts on radial mycelial growth of Rhizoctonia solani

The highest inhibition percentage $(72.2 \%)$ was recorded at $20 \%$ concentration by $D$. stramonium in radial mycelial growth of pathogen, followed by $E$. Globules $(70.7 \%)$, A. sativum, M. charantia $(63.3 \%$ and $61.1 \%$ ) inhibition respectively. Whereas, $A$. sativum has shown the same inhibition percentage of $63.3 \%$ at $10 \%$ and $20 \%$ extract concentration.
Calotropis exhibited least percentage inhibition $(11.1 \%)$ of mycelial growth $(11.1 \%)$ at $5 \%, 10 \%$ and $20 \%$ concentrations.

Effect of different plant extracts on radial mycelial growth of Macrophomina phaseolina:

Maximum inhibition in radial mycelial growth percentage induced by $M$. phasiolina was exhibited by $A$. sativum $(100.00 \%)$ at $5 \%, 10 \%$ and $20 \%$ concentrations. D. stramonium showed $0.0 \%, 27.7 \%$ and $57.7 \%$ inhibition at $5 \%, 10 \%$ and $20 \%$ concentration respectively. No inhibition in radial growth was recorded by $A$. indica, $P$. bysterophorus, $M$. charantia, E. globulus, Calotropis, A. vera and B. vulgaris.

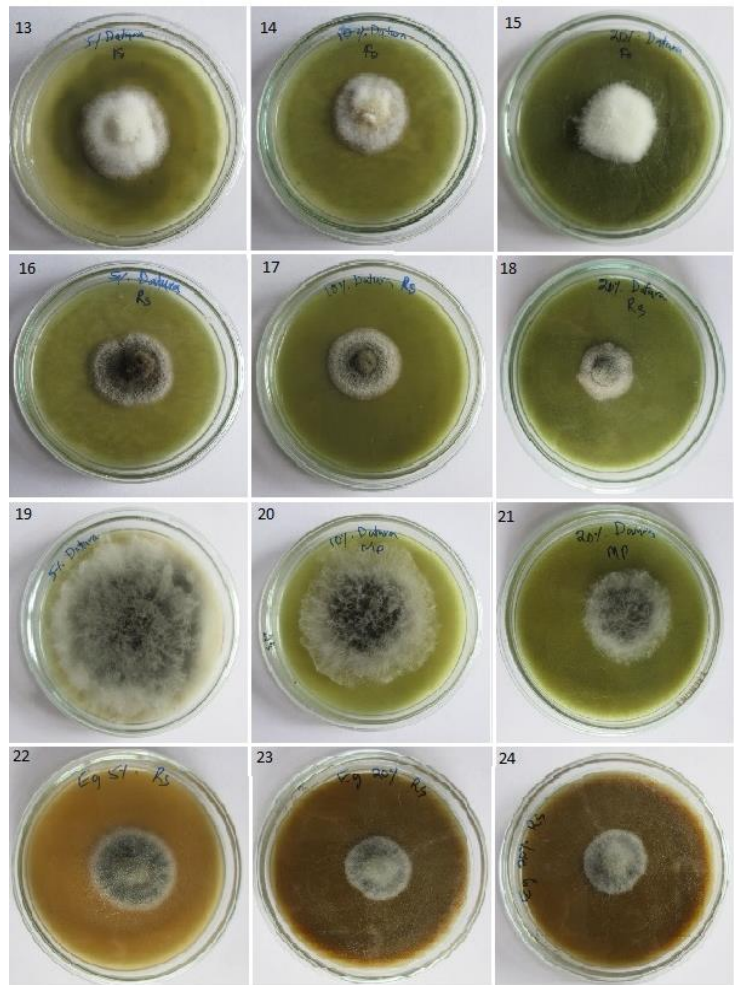

Plate 2. Petriplates showing effect of $D$. stromonium at $5 \%, 10 \%, 20 \%$ concentrations- Figs. 13-15: on Fom, 16-18: on R. solani, 19-21: on M. phaseolina; Fig. 22-24: Petriplates showing effect of E. globulus at $5 \%, 10 \%, 20 \%$ concentrations- Fig. 22-24: on $R$. solani.

Table 2. Effect of plant extracts on radial growth of Fusarium oxysporum

\begin{tabular}{|c|c|c|c|c|c|c|c|c|}
\hline Plant extract & Control (mm) & Inh $(\%)$ & $5 \%($ Mean \pm SD $)$ & Inh (\%) & $10 \%($ Mean \pm SD $)$ & Inh $(\%)$ & $20 \%$ (Mean \pm SD) & Inh $(\%)$ \\
\hline A. indica & 90 & 0 & $90.00 \pm 0.00$ & 0.0 & $90.00 \pm 0.00$ & 0.0 & $90.00 \pm 0.00$ & 0.0 \\
\hline P.histerophorus & 90 & 0 & $87.66 \pm 1.45$ & 2.6 & $85.00 \pm 1.52$ & 5.5 & $75.66 .33 \pm$ & 15.9 \\
\hline M.charantia & 90 & 0 & $77.00 \pm 1.00$ & 14.4 & $75.00 \pm 0.00$ & 16.6 & $68.00 \pm 0.00$ & 24.4 \\
\hline A.sativum & 90 & 0 & $42.66 \pm 1.45$ & 52.6 & $42.33 \pm 0.33$ & 52.9 & $33.00 \pm 0.00$ & 63.3 \\
\hline E.globulus & 90 & 0 & $47.00 \pm 1.00$ & 34.3 & $48.33 \pm 1.45$ & 46.0 & $34.33 \pm 0.66$ & 61.8 \\
\hline Calotropis & 90 & 0 & $90.00 \pm 0.00$ & 0.0 & $90.00 \pm 0.00$ & 0.0 & $90.00 \pm 0.00$ & 0.0 \\
\hline A.vera & 90 & 0 & $75.00 \pm 0.00$ & 16.6 & $75.00 \pm 0.00$ & 16.6 & $75.00 \pm 0.00$ & 16.6 \\
\hline B.vulgaris & 90 & 0 & $84.33 \pm 0.66$ & 6.3 & $81.66 \pm 1.66$ & 9.2 & $80.66 \pm 0.66$ & 10.3 \\
\hline D.stromonium & 90 & 0 & $35.00 \pm 0.00$ & 61.1 & $35.00 \pm 0.00$ & 61.1 & $35.00 \pm 0.00$ & 61.1 \\
\hline
\end{tabular}

Inh $(\%)=$ Inhibition $(\%)$ 
Table 3. Effect of plant extracts on radial growth of Rhizoctonia solani

\begin{tabular}{|c|c|c|c|c|c|c|c|c|}
\hline Plant extract & Control $(\mathrm{mm})$ & Inh (\%) & $5 \%($ Mean \pm SD $)$ & Inh (\%) & $10 \%($ Mean \pm SD $)$ & Inh (\%) & $20 \%($ Mean $\pm S D)$ & Inh (\%) \\
\hline A.indica & $90.00 \pm 0.0$ & 0 & $70.00 \pm 0.00$ & 22.2 & $70.00 \pm 0.00$ & 22.2 & $70.00 \pm 0.00$ & 22.2 \\
\hline P.histerophorus & $90.00 \pm 0.0$ & 0 & $72.33 \pm 1.45$ & 19.6 & $70.00 \pm 0.00$ & 22.2 & $61.00 \pm 3.05$ & 32.2 \\
\hline M.charantia & $90.00 \pm 0.0$ & 0 & $56.00 \pm 3.05$ & 37.7 & $44.00 \pm 3.51$ & 51.1 & $35.00 \pm 5.00$ & 61.1 \\
\hline A.sativum & $90.00 \pm 0.0$ & 0 & $34.00 \pm 1.00$ & 62.2 & $33.00 \pm 0.00$ & 63.3 & $33.00 \pm 0.00$ & 63.3 \\
\hline E.globulus & $90.00 \pm 0.0$ & 0 & $36.33 \pm 0.88$ & 59.6 & $35.00 \pm 1.00$ & 61.1 & $26.33 \pm 0.33$ & 70.7 \\
\hline Calotropis & $90.00 \pm 0.0$ & 0 & $80.00 \pm 0.00$ & 11.1 & $80.00 \pm 0.00$ & 11.1 & $80.00 \pm 0.00$ & 11.1 \\
\hline A.vera & $90.00 \pm 0.0$ & 0 & $55.00 \pm 0.00$ & 38.8 & $58.00 \pm 0.00$ & 38.8 & $60.00 \pm 0.00$ & 33.3 \\
\hline B.vulgaris & $90.00 \pm 0.0$ & 0 & $57.33 \pm 0.66$ & 36.3 & $53.66 \pm 0.88$ & 40.3 & $55.66 \pm 0.66$ & 38.1 \\
\hline D.stromonium & $90.00 \pm 0.0$ & 0 & $40.00 \pm 0.00$ & 55.5 & $33.00 \pm 0.00$ & 63.3 & $25.00 \pm 0.00$ & 72.2 \\
\hline
\end{tabular}

Inh (\%)= Inhibition (\%)

Table 4. Effect of plant extracts on radial growth of Macrophomina phaseolina

\begin{tabular}{|c|c|c|c|c|c|c|c|c|}
\hline Plant extract & Control (mm) & Inh (\%) & $5 \%$ (Mean \pm SD) & Inh (\%) & $10 \%$ (Mean \pm SD) & Inh (\%) & $20 \%$ (Mean \pm SD) & Inh (\%) \\
\hline A.indica & $90.00 \pm 0.0$ & 0 & $90.00 \pm 0.0$ & 0 & $90.00 \pm 0.0$ & 0 & $90.00 \pm 0.0$ & 0 \\
\hline P.histerophorus & $90.00 \pm 0.0$ & 0 & $90.00 \pm 0.0$ & 0 & $90.00 \pm 0.0$ & 0 & $90.00 \pm 0.0$ & 0 \\
\hline M.charantia & $90.00 \pm 0.0$ & 0 & $90.00 \pm 0.0$ & 0 & $90.00 \pm 0.0$ & 0 & $90.00 \pm 0.0$ & 0 \\
\hline A.sativum & $90.00 \pm 0.0$ & 0 & $00.00 \pm 0.0$ & 100 & $00.00 \pm 0.0$ & 100 & $00.00 \pm 0.0$ & 100 \\
\hline E.globulus & $90.00 \pm 0.0$ & 0 & $90.00 \pm 0.0$ & 0 & $90.00 \pm 0.0$ & 0 & $90.00 \pm 0.0$ & 0 \\
\hline Calotropis & $90.00 \pm 0.0$ & 0 & $90.00 \pm 0.0$ & 0 & $90.00 \pm 0.0$ & 0 & $90.00 \pm 0.0$ & 0 \\
\hline A.vera & $90.00 \pm 0.0$ & 0 & $90.00 \pm 0.0$ & 0 & $90.00 \pm 0.0$ & 0 & $90.00 \pm 0.0$ & 0 \\
\hline B.vulgaris & $90.00 \pm 0.0$ & 0 & $90.00 \pm 0.0$ & 0 & $90.00 \pm 0.0$ & 0 & $90.00 \pm 0.0$ & 0 \\
\hline D.stromonium & $90.00 \pm 0.0$ & 0 & $90.00 \pm 0.0$ & 0 & $65.00 \pm 0.0$ & 27.7 & $38.00 \pm 0.0$ & 57.7 \\
\hline
\end{tabular}

Inh (\%)= Inhibition (\%)

\section{Discussion}

The inhibitory effect of the plant extracts might be attributed to the presence of some antifungal toxicants. Several authors have also reported the fungicidal activity in wide variety of taxa. The presence of antifungal compounds in higher plants is well recognised and considered valuable for plant disease control (Singh and Dwivedi, 1987).

In the present study, it was noticed that the extract of $A$. sativum revealed considerable antifungal activity against the tested pathogens. Our results are in correlation with earlier work of Avasthi et al., (2005), Sehajpal et al. (2009) on A. sativum, which showed $100 \%$ inhibition of the mycelial growth of A. niger at $20 \%$ concentration. This fungicidal activity of $A$. sativum possibly related to organo sulphur compound including allicin (Hovana et al., 2011). These compounds showed better antifungal activity than both antibiotics streptomycin and ampicillin (Illic et al., 2012).

Antifungal activity of Azadirachta indica has been reported to have inhibitory effects on Rhizoctonia solani (Sivakadadacham, 1988; Sharma and Jnandaik, 1994). The bioactivity of neem extracts has been attributed by various compounds such as nimbin, nibbidin, and salannin and most important antifungal compound is azadirachtin. Our results demonstrate that D. stramonium, E. globulus, $A$. sativum, $M$. charantia extracts effectively suppressed the radial mycelial growth of $\mathrm{R}$. solani. $M$. charantia contains an array of biologically active plant chemicals including triterpenes, proteins and steroids. The antifungal activity E. globulus extract may be attributed to the presence of some compounds. The major component was 1,8 -cineole $(85.8 \%)$, B-pinine $(7.2 \%)$ and B-myrcene $(1.5 \%)$.

\section{Conclusion}

Results of the present study indicate that the tested extracts showed fungicidal activity against the tested pathogens. Plant extracts can be exploited as natural fungal toxicants to manage the growth of pathogenic fungi and thus reduce the dependence on fungicides. All over the world, attention has been drawn towards the exploitation of higher plant products as novel chemo-therapeutants in plant protection. Because of non-phytotoxicity, systemicity, easy bio-degradability and the stimulatory nature of host metabolism, plant products possess the potential to be of value in pest management (Mishra and Dubey, 1994). Some plant extracts such as $A$. sativum, D. stramonium, E. globules could be a good antifungal efficacy, which may be used for formulating new, safer and eco-friendly fungicides. It is therefore, encouraging to identify and characterize the active principle. Moreover, because of the water-soluble nature of the toxic principle, it is ideal for developing into herbal pesticides.

\section{Acknowledgement}

The authors are thankful to Head, Department of Botany, Osmania University for providing necessary laboratory facilities.

\section{References}

1. Altinok HH. First reports of Fusarium wilt of eggplant caused by Fusarium oxysporum f. sp. melongenae in Turkey. Plant Pathol 54 (2005): 577.

2. Avasthi S, Guatam AK, Bhadauria. Antifungal activity of plant products against Aspergillus niger: A potential application in the control of a spoilage fungus. Int J 2 (2005): 53-55. 
3. Gerretsen FC, Haagsma N. Occurrence of antifungal substances in Brassica repa, Brassica olleracea and Beta vulgaris. Nature (1951): 168-659.

4. Hoes JA. Macrophomina phaseolina causal agent of charcoal rots of sunflower and other crops. Agriculture Research Station, Modren Manitoba, Canada (1985).

5. Hovana EIK, James US, James E, Egbobor EM, Egba AG, Eta ES, Nwakaku OA. Antibacterial and phytochemical studies of Allium sativum. N Y Sci J 4 (2011): 123-128.

6. Ilic D, Nikolic V, Ciric A, Sokovic M, Stanojkovic T. Cytotoxicity and antimicrobial activity of allicin and its transformation products. J Med Plants Res 6 (2012): 59-65.

7. Kata J. Physical and cultural methods for the management of soil borne pathogens. Crop Protection 19 (2000): 725-731.

8. Kumar BP, Charya MAS, Reddy SM. Screening of plants extracts for antifungal properties. New Botanist 6 (1979): 41-43.

9. Mishra AK, Dubey NK. Evaluation of some essential oils for their toxicity against fungi causing deterioration of stored food commodities. Appl and Envir Microbiol 60 (1994): 1101-1105.

10. Naidu VD, John VT. In vitro inhibition of rice fungal pathogens by extracts from higher plants. Int Rice Res News letter 6 (1982): 12.

11. Nene YL, Thapliyal PK. Fungicides in plant disease controls. 3rd Ed, Oxford and IBH publishing Co. New Delhi (1993): 531.

12. Parajuli DP, Gyawali VT, Shrestha BM. A Manual of the Important Non-Timber Forest Products in
Nepal. Training and manpower development in C.F.M. Pokhara, Nepal (1998).

13. Pullaiah T. Flora of Telangana in 3 Vols. Astral International (P) Ltd., New Delhi- India (2015).

14. Seema M, Devaki NS. Effect of some essential oils on Rbizoctonia solani Kuhn infecting flue-cured Virginia tobacco. J of Biopesticides 3.3 (2010)): 563 566.

15. Sehajpal A, Arora S, Kaur P. Evaluation of plant extracts against Rhizoctonia solani causing sheath blight of rice. The J of Plant Prot Sci 1.1 (2009): 2530 .

16. Sharma VN, Jandaik CL. Effect of some plant materials in controlling different moulds in Agaricus bisporus (Lang) Imb. J Ind Mycol and Pl Pathol 24.30 (1994): 183-185.

17. Singh RK, Dwivedi RS. Effect of oils on Sclerotium rolfsii causing foot-rot of barley. Ind Phytopathol 40 (1987): 531-33.

18. Sivakadadcham B. Green manure for the control of soil-borne pathogens. Tropical Agriculturist 114 (1988): 163-164

19. Vincent JM. Distortion of fungal hyphae in the presence of certain inhibitors. Nature 159 (1947): 850-850.

\section{Cite this article as:}

Ramaraju Cherkupally, Srinivasa Reddy Kota, Hindumathi Amballa and Bhumi Narasimha Reddy. In vitro antifungal potential of plant extracts against Fusarium oxysporum, Rhizoctonia solani and Macrophomina phaseolina. Annals of Plant Sciences 6.9 (2017) pp. 1676 1680

doi: http://dx.doi.org/10.21746/aps.2017.9.2 